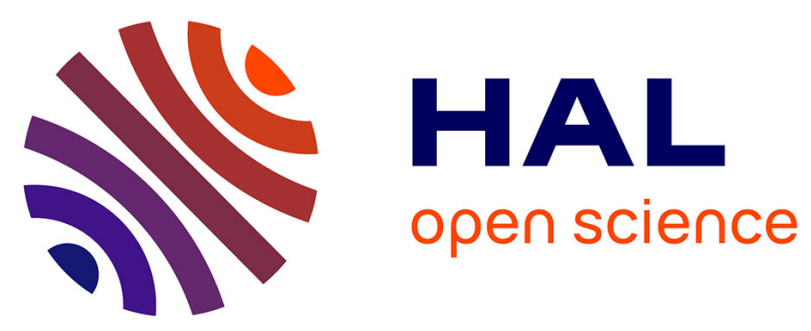

\title{
Comments on "Frequency Response of the Noise Conversion from Relative Intensity Noise to Phase Noise in the Photodetection of an Optical Pulse Train"
}

Ha Duy Phung, Michel Lintz

\section{- To cite this version:}

Ha Duy Phung, Michel Lintz. Comments on "Frequency Response of the Noise Conversion from Relative Intensity Noise to Phase Noise in the Photodetection of an Optical Pulse Train". IEEE Photonics Technology Letters, 2014, 26 (19), pp.1994. 10.1109/LPT.2014.2310814 . hal-01058444

\author{
HAL Id: hal-01058444 \\ https://hal.science/hal-01058444
}

Submitted on 26 Aug 2014

HAL is a multi-disciplinary open access archive for the deposit and dissemination of scientific research documents, whether they are published or not. The documents may come from teaching and research institutions in France or abroad, or from public or private research centers.
L'archive ouverte pluridisciplinaire HAL, est destinée au dépôt et à la diffusion de documents scientifiques de niveau recherche, publiés ou non, émanant des établissements d'enseignement et de recherche français ou étrangers, des laboratoires publics ou privés. 


\title{
Comment to "Frequency Response of the Noise Conversion From Relative Intensity Noise to Phase Noise in the Photodetection of an Optical Pulse Train", K. Wu et al, IEEE Photon. Technol. Lett. 23 $\left(n^{\circ} 8\right) 2011$, p. 468
}

\author{
Duy-Ha Phung, Michel Lintz
}

Laboratoire ARTEMIS, Univ. Nice Sophia, Observatoire de la Cote d'Azur and CNRS, Bd de l'Observatoire, 06300 Nice, France (e-mail: michel.lintz@oca.eu).

\begin{abstract}
It is shown that the results presented in the article by Wu et al. (IEEE Photon. Technol. Lett. 23 ( ${ }^{\circ}$ 8) 2011, pp. 468-470), and attributed by the authors to amplitude-to-phase conversion in the photodetector, do not originate in the photodetector under test, due to the power dependence observed. More recent results show that conversion effects with the same size and frequency dependence are observed in passively mode-locked NPR (non-linear polarization rotation) mode-locked lasers.
\end{abstract}

Index Terms - Phase measurement, Phase noise, Photodetectors, mode-locked lasers.

$I^{n}$

their article, K. Wu et al. [1] address the problem of the amplitude-to-phase conversion in 1 photodetectors, already observed in earlier publications. They present a particularly simple set-up, that may provide a convenient means to characterize the AM-to-PM conversion in high bandwidth photodetectors. They use a $2.4 \mathrm{~mW}$ free-running passively mode-locked laser at $147 \mathrm{MHz}$ repetition rate, and modulate the power of the laser at audio frequencies by modulating the power of the pump diode. They subsequently detect the pulse train emitted by the mode-locked laser using a $2 \mathrm{GHz}$ photodiode. The signal of the photodiode is analyzed by a signal analyzer FSUP26, which can deliver

- the relative intensity noise power spectrum and the phase noise of the $147 \mathrm{MHz}$ signal, separately, (Fig. 2 a- and b-, respectively) as a function of the offset frequency

- or the spectrum, in $\mathrm{dBm}$ of the signal around $147 \mathrm{MHz}$, Fig. 4.

Both figures show that the $147 \mathrm{MHz}$ signal is phase-modulated at the frequency of the power modulation and at its harmonics. In Fig. 4, the phase modulation appears as a an asymmetry in the side bands: the asymmetry $\Delta P$ is plotted in $\mathrm{dB}$, in different conditions.

The important point is to confirm that the effect originates in the photodiode and not in the generation of the power-modulated pulse train. To confirm this, one can insert attenuators in front of the photodiode. As the mean power is reduced by a factor $\mathrm{K}$, the amplitude of the power modulation is 
also reduced by a factor of $K$, keeping the relative intensity noise (RIN) constant. Then one expects that the amplitude of the phase change will be accordingly reduced by a factor of K. In other words, one expects that the conversion ratio from RIN to phase noise is proportional to optical power. But data on fig. 3 show that when an attenuator is inserted the conversion ratio from RIN to phase noise is constant. The same observation can be made from Fig. 4: the ratio $\Delta P$, plotted in $\mathrm{dB}$ in Fig. 4-c, remains constant (less than $0.3 \mathrm{~dB}$ variation for a $6 \mathrm{~dB}$ variation of the RF power), whatever the attenuation of the optical power. The expected linearity is not observed.

It may seem naive to expect linearity with optical power in amplitude-to-phase conversion in photodetectors. With strong optical pulses a significant distortion occurs, as observed by Ivanov et al. [2] and others. But, as shown in [2], the non-linear behavior is essentially observed in high harmonics of the signal. For low frequency harmonics, no significant non-linearity is expected at a power of 2.4 $\mathrm{mW}$ or less. This is particularly well demonstrated in [3], where $\mathrm{K}$. Wu et al. have varied the optical power at the photodiode using a variable optical attenuator and extensively studied the resulting temporal profiles of the pulses delivered by a $10 \mathrm{GHz}$ photodiode. Non-linear features are specifically observed in high harmonics of the detected signal. With low harmonics of the signal, or more generally with harmonics at frequencies $<<1 \mathrm{GHz}$, the RIN to phase noise conversion coefficient increases with optical power. This is particularly clear in Fig. 5-c (dotted line) corresponding to the fundamental frequency, where the RIN to phase noise conversion factor shows linear behavior. Same trend is observed in Fig. 5-b, and 6, for frequencies $\ll<1 \mathrm{GHz}$. Note that in the graphs of ref. [3] the horizontal axis does not start exactly at zero $\mathrm{mW}$ optical power.

For these reasons we believe that the absence of a dependence of the RIN-to-phase noise conversion factor on the optical power in [1] raises suspicion that the observed phase noise may not be due to conversion in the photodetector.

As to the possible origin of the phase noise observed in [1], ref. [4] brings some more insight, by studying the pump-to-phase conversion in two different $1.5 \mu \mathrm{m}$ passively mode-locked lasers in conditions where the authors can check that conversion in the photodetector is negligible. They measure the pump-to-phase noise conversion ratio in a NPR laser, and obtain the values listed in Table I.

TABLE I

PUMP-TO-PHASE NOISE CONVERSION RATIO

\begin{tabular}{|c|c|}
\hline $\begin{array}{c}\text { frequency } \\
(\mathrm{kHz})\end{array}$ & $\begin{array}{c}\text { pump-to-phase noise } \\
\text { conversion ratio (dB) } \\
\text { (from [4], Fig. 2-a, blue } \\
\text { curve) }\end{array}$ \\
\hline 5 & -3 \\
\hline 10 & -7 \\
\hline 20 & -9 \\
\hline 30 & -14 \\
\hline
\end{tabular}




\begin{tabular}{|c|c|}
\hline 40 & $-16 /-17$ \\
\hline 60 & -22 \\
\hline
\end{tabular}

Not only these values are orders of magnitude above the estimate of $10^{-9}$ obtained from the theoretical analysis mentioned in [1], but they also match very well the values of the conversion ratio in [1], Fig. 3, up to $30 \mathrm{kHz}$.

We conclude that in ref. [1], at least up to $30 \mathrm{kHz}$ offset frequency, the RIN-to-phase noise conversion in the laser dominates the observed phase noise just as in ref. [4]. More complete characterization, such as performed in ref. [3], is required before conclusively assigning the power-to-phase conversion observed in [1] at $40 \mathrm{kHz}$ and above to the laser or to the photodiode.

\section{REFERENCES}

[1] K. Wu, C. Ouyang, J. H. Wong, S. Aditya, P. Shum,,"Frequency response of the noise conversion from relative intensity noise in the photodetection of an optical pulse train," IEEE Photon. Technol. Lett. vol. 23, n 8, pp. 468-470, Apr. 2011.

[2] E. N. Ivanov, S. A. Diddams, and L. Hollberg, "Study of the excess noise associated with demodulation of ultra-short infrared pulses," IEEE Trans. Ultrason. Ferroelectr. Freq. Control. vol. 52, no 7, pp. 1068-1074, Jul. 2005.

[3] K. Wu, P. P. Shum, S. Aditya, C. Ouyang, J. H. Wong, H. Q. Lam, and K. E. K. Lee, "Characterization of the excess noise conversion from optical relative intensity noise in the photodetection of modelocked lasers for microwave signal synthesis," J. Lightwave Technol. vol. 29, no 24, pp. 3622-3631, Dec. 2011.

K. Wu, P. P. Shum, S. Aditya, C. Ouyang, J. H. Wong, H. Q. Lam, and K. E. K. Lee, "Noise conversion from pump to the passively mode-locked fiber lasers at $1.5 \mu \mathrm{m}$," Opt. Lett. , vol. 37, no. 11, pp. 19011903, Jun. 2012. 